\title{
Study on Mechanical Behaviors of Orthotropic Deck of Highway Bridge
}

\author{
Bing $\mathrm{Han}^{1, \mathrm{a}}$,Qianhui $\mathrm{Pu}^{1, \mathrm{~b}}$, Leiping $\mathrm{Xu}^{1-2, \mathrm{c}}$, Shili Yang ${ }^{1, \mathrm{~d}}$, Liangjun Chen ${ }^{1, \mathrm{e}}$ \\ ${ }^{1}$ School of Civil Engineering, Southwest Jiaotong University, Chengdu 610031,China; \\ ${ }^{2}$ China Railway Major Bridge Reconnaissance \& Design Institute Co., Ltd.,China
}

ahanbing0218_swjtu@163.com, ${ }^{b}$ qhpu@vip.163.com, ${ }^{\text {'xulp@ @brdi.com.cn, }{ }^{d} 1162532084 @ q q . c o m}$

${ }^{\mathrm{e}}$ chen20081601@163.com

Keywords: Orthotropic Deck; Mechanic Behavior; Finite Element Method; Welding Details

\begin{abstract}
In order to investigate mechanic behaviors of the orthotropic deck welding conformation details of highway steel bridge, take Zhongdu Yangtze River Bridge located in Jiangjin of Chongqing district as an engineering background, the 3-dimension spatial section model of steel box girder was firstly established based on the numerical finite element method, and then the stress level of welding conformation including the top plate of orthotropic deck, stiffening rib and transverse diaphragm was studied. The numerical analyzed results show that the stress level of welding conformation is mainly influenced by the second system and the third system. The mechanical performance of box girder is specifically represented as global bending action, global shearing action and local supporting action, which reflects significant local stress state. Also, the degree of the above mentioned actions for different conformation details is different.
\end{abstract}

\section{Introduction}

Orthotropic deck has advantages of light weight, high strength, large bearing capacity, fast installation speed, beautiful appearance and wide application range, which is frequently used in long-span bridge structures. However, due to the complicated space welding structures, it is easy to cause the fatigue crack of the orthotropic bridge deck [1][6]. For example, the fatigue crack was detected at welding locations between the stiffening rib and top deck as well as the web after the Britain's Severn bridge had been operated over 5 years [2]. Also, the serious box girder cracking phenomenon at welding location between the top deck and stiffening rib was also observed in Humen Yangtze River bridge of China in 2007 [3]. Therefore, a lot of research works of mechanic behaviors of the orthotropic deck have been studied by many scholars [4][5].

Zeng Zhibin [6] investigated the position and the cause of the fatigue crack of orthotropic plate. Han Bing[7] analyzed the hot spot stress of the structural details and a modeling method of the orthotropic deck details was recommended. Furthermore, some researchers [8][9][10] studied the stress characteristics and fatigue strength through full-scale model test.

Orthotropic deck is composed of top plate, longitudinal stiffening rib and diaphragm, and a series of complex welding process is used for connecting them. The orthotropic deck is one of the most important load-bearing and force transferring structure for bridge girder, and, consequently, a global analysis of mechanical behavior of the orthotropic deck should be taken. Taken Zhongdu Yangtze River Bridge as an engineering background, and the mechanical behavior of the orthotropic deck is studied based on the finite element method, and the stress composition of different welding structure details was analyzed.

\section{Finite element model}

Zhongdu Yangtze River Bridge is a twin towers suspension bridge with the main span of $600 \mathrm{~m}$, and the arrangement of spans is $(50+600+65) \mathrm{m}$. The streamlined flat sealing steel box girder is used in the girder of the main span, and the orthotropic plate structure is adopted in bridge deck and floor, and the main section of the bridge features a two-way six-lane motor traffic. The box girder is 3.0m high, 33m wide, and a total of 40 longitudinal trapezoid stiffened ribs are used on the deck. 
The software used in this thesis is the Large Finite Element Analyze Software ANSYS, and the finite element model, which use shell element to simulate the steel structure and use solid element to simulate the concrete structure, is with a length of $25 \mathrm{~m}$. The finite element geometric model is shown in Fig.1, and the layout of stress measurement points of orthotropic deck is shown in Fig.2, where DB represents the measurement points on the top plate, JJL represents the measurement points on the web of the trapezoid stiffened rib, and HGB represents the measurement points on the diaphragm.

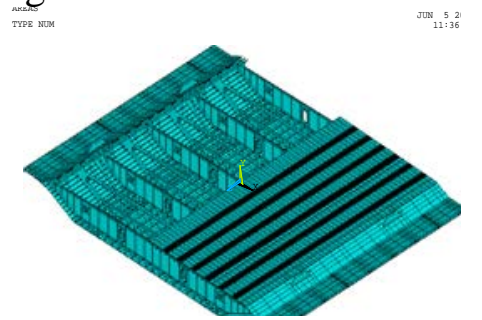

Fig.1 Finite element model of steel girder

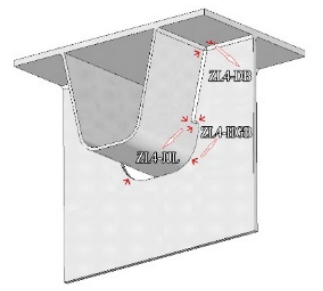

Fig.2 Layout of measurement points of orthotropic deck

The live traffic load of General Code for Design of Highway Bridges and Culverts (JTG D60-2004) was used for loading, and the moving traffic loads were located on the center line of every lane, the transverse and longitudinal position of live loads was shown in Fig.3.

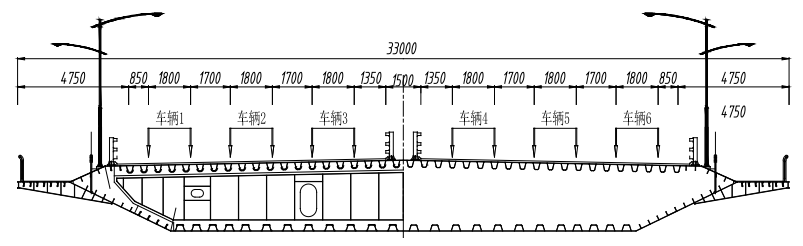

(a) Transverse position of moving load

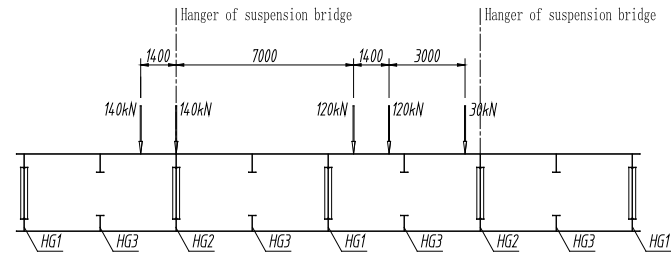

(b) Longitudinal position of moving load

Fig.3 Loading position of the orthotropic plate (mm)

\section{Analysis of simulation result}

The stress state of measurement points of deck, the web of rib and the diaphragm is shown in Fig.4. In the figure, 1\# means that the point is located on the inner side, however 2\# means that the point is located on the outer side.

According to the layout of the live loads, the wheel loads are acting on the 4\# rib, 7\# rib, 10\# rib, $13 \#$ rib, $16 \#$ rib and 19\# rib, and obvious local stress variations happen in the loading positions, which is shown in Fig.4, the reason of this stress distribution is that the stress of the orthotropic bridge deck is mainly composed of the following three stress states.

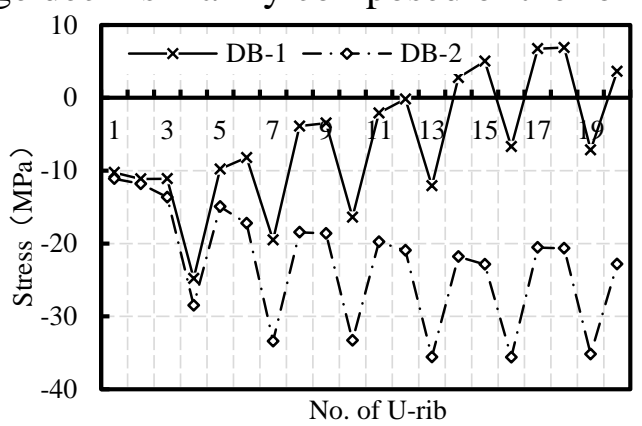

(a) Stress of deck

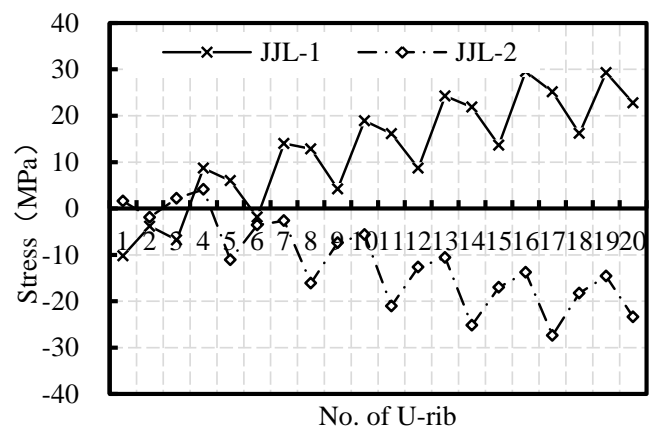

(b) Stress of U-rib 


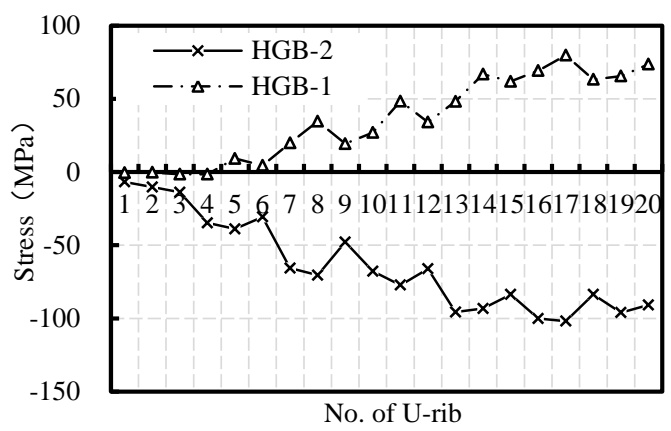

(c) Stress of diaphragm

Fig.4 Stress calculation results of welding structures

\section{The Global Bending Action}

The bending, shear deformation of steel girder will happen under the action of live load and the supporting of hangers, and the deformation form of steel girder of highway suspension bridge is shown in Fig.5. The in-plane compressive stress happens in the deck under the transverse bending action of steel girder, shown in Fig.4-a, and the stress of deck is greater where the rib is closed to the central axis of bridge because of the larger bending deformation of the girder happens in the position of the bridge center. The global bending action belongs to the second system of orthotropic deck.

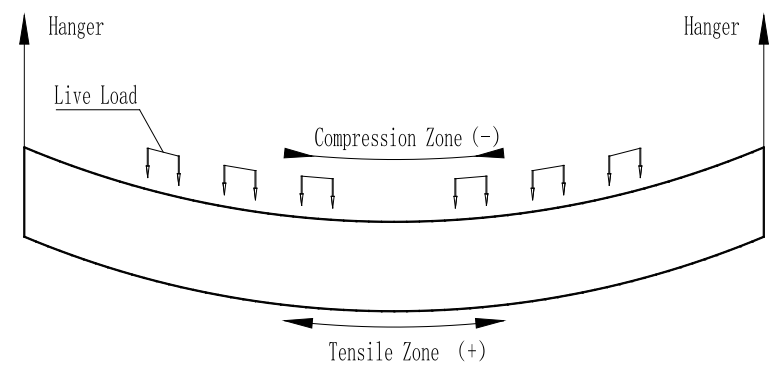

Fig.5 Deformation state of the global bending action

\section{The Global Shearing Action}

The diaphragm will produce shear deformation under the effect of live load, and the shear deformation increases with the distance from the center of the bridge. The shear deformation of the diaphragm will cause the bending of the deck and the web of the stiffening rib. The deformation state of the deck is shown in Fig6-a. The deck of the two sides of the stiffening rib is respectively generated out-plane upward bending and downward bending under the global shearing action, which can lead opposite stress states on the two side of the deck. In Fig.4-a, the stress distribution of measuring point of deck on the left side is different from that of the right, which is the result of this kind of shearing action.

Due to the shear deformation of the diaphragm, it can also cause the bending of the web of the stiffening rib. The outward deformation will happen on one side of the web and the inward deformation will happen on the other, and the lower edge of the cutout of diaphragm can also produce the deformation state of compression in the inner side and tension in the outer side, which is shown in Fig.6-b. The bending deformation increase with the shearing effect, and the global bending action belongs to the second system of orthotropic deck.

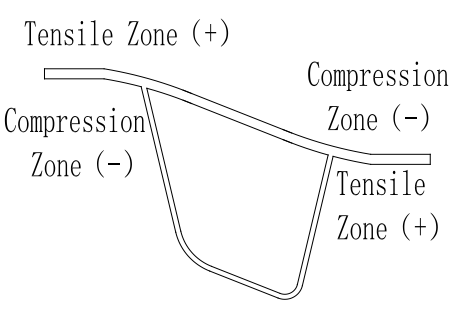

(a) Deformation state of deck

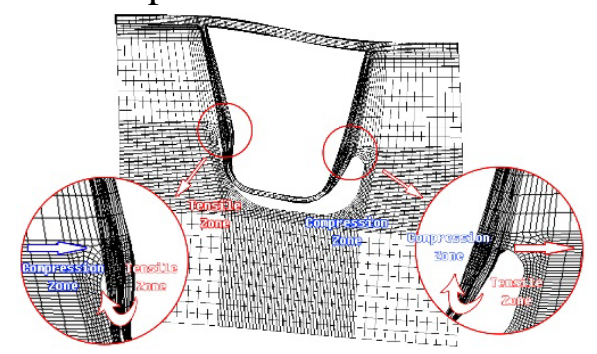

(b) Deformation state of the web of the stiffening rib and the diaphragm

Fig.6 Deformation state of the global shearing action 


\section{The Vertical Local Supporting Action}

The deck under the direct action of live load will be supported by web of the stiffening rib and the diaphragm. The deck of both sides of the stiffening rib web plate presents the downward bending deformation caused by the local supporting action, therefor, the top surface layer is on the tensile zone and the bottom surface layer is on the compression zone, and the local compressive stress concentration will be generated at the bottom of the deck. The deformation state of the deck is shown in Fig7-a. The diaphragm has a local support for the rib, and the tensile membrane stress is produced near the weld toe of the web of stiffening rib and diaphragm. Compressive stress is generated at the cutout of diaphragm under the local supporting action. The stress states of web of rib and diaphragm are shown in Fig.7-b, and the serrated fluctuation of stress in Fig.4 is caused by the local supporting action. The vertical local supporting action belongs to the third system of orthotropic plate.

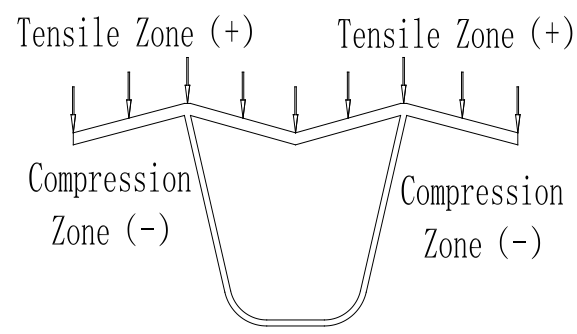

(a) Deformation state of deck

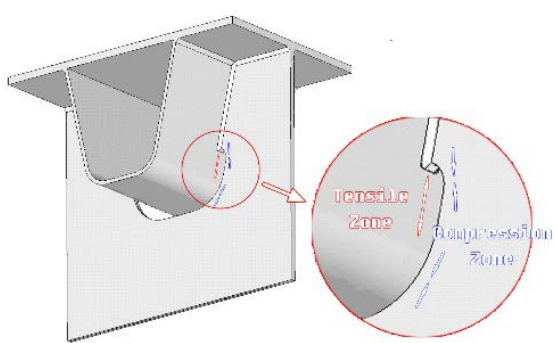

(b) Stress states of the web of the stiffening rib and the diaphragm

Fig.7 Deformation state of the vertical local supporting action

\section{Conclusion}

In this paper, take Zhongdu Yangtze River bridge located in Jiangjin of Chongqing district as an engineering background, the spatial shell element was adopted to establish analysis model implemented by ANSYS platform, the mechanic behaviors of the orthotropic deck welding conformation details of highway steel bridge was then studied. The conclusions are summarized as follows:

1 The stress state of welding conformation details of orthotropic steel bridge deck is mainly determined by the second system and the third system.

2 The global bending action is caused by the transverse bending deformation of the box girder which largely affect the transverse stress state of top deck and transverse diaphragm.

3 The global shearing action is caused by the transverse shearing deformation of the transverse diaphragm which may lead to bending deformation out-of-plane for the top deck and stiffened rib, stress concentration phenomenon at welding conformation. This action is also the dominant factor of stress concentration at the free edge of transverse diaphragm incision.

4 The vertical local supporting action exists among the top deck, stiffening rib and transverse diaphragm which is directly caused by vehicle load. This action may lead to large local bending deformation, increase the stress concentration to top deck, produce in-plane local tension stress to welding seam of stiffening rib and vertical compressive stress to the free edge incision of transverse diaphragm.

\section{References}

[1] WANG Chun-sheng, FENG Ya-cheng. Review of Fatigue Research for Orthotropic Steel Bridge Deck [J].Steel Construction, 2008, 24(9):10-13,32

[2] WOLCHUK R. Lessons from Weld Cracks in Orthotropic Decks on Three European Bridges [J]. Journal of Structural Engineering, 1992,116(1):75-84.

[3] Ding Nan, Shao Xudong. Study on Fatigue Performance of Light-Weight Composite Bridge Deck [J]. China Civil Engineering Journal, 2015，48(1): 74-81

[4] TIAN Qi-xian, GAO Li-qiang, DU Xin-xi. Study of Influences of Deck Plate Structural Design 
on Fatigue Performance of Orthotropic Bridge Deck. [J]. Bridge Construction, 2016, 46(1): 18-23.

[5] BU Yi-zhi, YANG Shao-lin, CUI Chuang, et al. Influence of Wheel Trace Transverse Distribution on Fatigue Stress Range of Steel Deck [J] . Bridge Construction, 2015, 45(2) : 39-45.

[6] ZENG Zhibin. Classification and Reasons of Typical Fatigue Cracks in Orthotropic Steel Deck [J]. Steel Construction, 2011, 26(2): 9-15.

[7] HAN Bing, PU Qianhui, SHI Zhou. Study of Calculation Methods for Hot Spot Stress of Welded Structure of Bridge Orthotropic Plate[J]. Bridge Construction, 2009, 24 (5): 33-37.

[8] WANG Chunsheng, FU Bingning, ZHANG Qin, et al. Fatigue Test on Full-scale Orthotropic Steel Deck [J]. China Journal of Highway and Transportation, 2013, 26(2): 69-76.

[9] TANG Liang, HUANG Liji, LIU Gao, et al. Fatigue Experimental Study of A Full-scale Steel Orthotropic Deck Model [J]. China Civil Engineering Journal, 2014, 47(3):112-122.

[10]ZHANG Qinghua, CUI Chuang, BU Yizhi, et al. Experimental study on fatigue features of orthotropic bridge deck through full-scale segment models, [J]. China Civil Engineering Journal, 2015, 48(4): 72-83. 